УДК 699.812.3

ПРИМЕНЕНИЕ КРЕМНЕЗЕМНЕВОГО НАПОЛНИТЕЛЯ ДЛЯ ПОВЫШЕНИЯ ОГНЕСТОЙКОСТИ ДРЕВЕСИНЫ

APPLICATION OF SILICA FILLER TO INCREASE FIRE RESISTANCE OF WOOD

\title{
А.М. Газизов
}

Уфимский государственный нефтяной технический университет, г. Уфа, Российская Федерация

Уральский государственный лесотехнический университет, г. Екатеринбург, Российская Федерация

И.И. Дудниченко

Уральский государственный лесотехнический университет, г. Екатеринбург, Российская Федерация

Ф.ШІ. Хафизов

Уфимский государственный нефтяной технический университет, г. Уфа, Российская Федерация

Asgat M. Gazizov

Ufa State Petroleum Technological University, Ufa, Russian Federation Ural State Forestry Engineering University,

Yekaterinburg, Russian Federation

Ilya I. Dudnichenko

Ural State Forestry Engineering University,

Yekaterinburg, Russian Federation

Sh. Khafizov

Ufa State Petroleum Technological University, Ufa, Russian Federation e-mail: ashatgaz@mail.ru 
Аннотация. Для деревообрабатывающей промышленности защитная обработка древесины является одной из злободневных проблем, поскольку древесина - материал биологический, он подвержен всевозможным биологическим воздействиям, таким как гниение, поражение паразитами, грибами. Огнезащита древесины является немаловажным фактором также потому, что сохранение конструкцией физико-механических свойств во время непосредственного действия огня - крайне важный показатель для деревянного домостроения и другого использования древесины.

На сегодняшний день рынок обрабатывающих жидкостей и намазок для древесины многогранен и многочислен. Одной из основных проблем является качество препаратов и их соответствие требованиям ГОСТ по защитным показателям. Качество определяют по многочисленным показателям, основными из которых являются следующие: глубина пропитки (позволяет сделать вывод о том, законсервирована заготовка или нет); время до обугливания (показывает сколько времени может выдержать древесина без потери своих физико-механических показателей).

В статье обосновано использование антипиреновых пропиток, представлены варианты огнеупорной пропитки, состав огнезащитной пропитки, анализ проведения испытаний на огнестойкость, определение класса огнестойкости. Основа антипереновой пропитки - кремнезём концентрации $2,65 \%$.

В результате проведения огневых испытаний установлено, что на рассматриваемом отрезке времени (от 1 до 24 ч) величина поглощения с течением времени растет, что характеризует достаточную глубину пропитки древесины антипиреновым составом. Установлено, что с увеличением времени выдержки образцов время тления возрастает монотонно. Похожая ситуация наблюдается и со временем обугливания, но следует отметить, что график оказался более монотонным на отрезке времени от 4 до 18 ч. 
Abstract. For the woodworking industry, the protective treatment of wood is one of the burning problems, since wood is a biological material, it is susceptible to all kinds of biological influences, such as decay, parasite and fungus damage. Fire protection of wood is an important factor also because the preservation of the physicomechanical properties of the structure during the direct action of fire is an extremely important indicator for wooden housing construction and other uses of wood.

Today, the market for processing fluids and spreading agents for wood is multifaceted and numerous. One of the main problems is the quality of the drugs and their compliance with the requirements of GOST for protective indicators. Quality is determined by numerous indicators, the main of which are the following: depth of impregnation (allows us to conclude whether the workpiece is preserved or not); time to carbonization (shows how long the wood can withstand without losing its physical and mechanical properties).

The article substantiates the use of flame retardant impregnations, presents options for refractory impregnation, the composition of fire-retardant impregnation, analysis of fire tests, determination of the class of fire resistance. The basis of anti-foam impregnation is silica concentration of $2.65 \%$.

As a result of the fire tests, it was found that in the considered period of time (from 1 to 24 hours) the absorption value increases over time, which characterizes the sufficient depth of wood impregnation with a flame retardant composition. It has been established that with an increase in the exposure time of the samples, the smoldering time increases monotonously. A similar situation is observed with the time of carbonization, but it should be noted that the schedule turned out to be more monotonous over a period of time from 4 to 18 hours.

Ключевые слова: древесина; огнезащитный состав; антипирены; прочность; время обугливания; время тления

Key words: wood; flame retardant; flame retardants; strength; charring time; smoldering time 
Для деревообрабатывающей промышленности защитная обработка древесины является одной из злободневных проблем, поскольку древесина - материал биологический, он подвержен всевозможным биологическим воздействиям, таким как гниение, поражение паразитами, грибами. Огнезащита древесины является немаловажным фактором также потому, что сохранение конструкцией физико-механических свойств во время непосредственного действия огня - крайне важный показатель деревянного домостроения и другого использования древесины [1-4].

На сегодняшний день рынок обрабатывающих жидкостей и намазок для древесины многогранен и многочислен. Разобраться, какой препарат необходим в той или иной ситуации достаточно проблематично.

Одной из основных проблем является качество препаратов и их соответствие по защитным показателям требованиям ГОСТ. Качество определяют по многочисленным показателям, основными из которых являются следующие: глубина пропитки (позволяет сделать вывод о том, законсервирована заготовка или нет); время до обугливания (показывает, сколько времени может выдержать древесина без потери своих физикомеханических показателей).

Для определения класса огнезащиты и этапов проведения испытаний используем ГОСТ Р 53292-2009 «Огнезащитные составы и вещества для древесины и материалов на ее основе. Общие требования. Методы испытаний» [5].

Предлагаемый огнезащитный состав - полученная пропиточная жидкость соответствует классу «Лаки, огнезащитные».

Изготовление пропиточной жидкости. Необходимо в воду насыпать кремнезем и тщательно перемешать. Растворение кремнезема в воде представляет собой процесс деполимеризации посредством гидролиза, в результате установления равновесия между процессами деполимеризации и полимеризации получается ортокремневая кислота $\mathrm{Si}(\mathrm{OH})_{4}$ концентрацией $2,65 \%$. 
Полученный состав представляет собой раствор на водной основе, образующий на поверхности образцов тонкую защитную пленку. Для испытаний было принято решение использовать сосну с влажностью $8 \pm 2 \%$. Выпиливание произведено с удалением всех видимых пороков древесины, а также без содержания смоляных включении. Проведена предварительная шлифовка образцов, чтобы устранить загрязнение сердцевинных лучей в образцах. Образцы пронумерованы для удобства обработки в дальнейшем. Далее образцы были погружены в пропиточную жидкость. Следует отметить, что заготовки были полностью погружены в жидкость благодаря утяжелителям, которые установлены сверху контейнера, чтобы предотвратить непропитку одной из сторон. Выдержка образцов в огнезащитном составе проведена в течение следующих временных показателей: 1, 2, 4, 7, 12, 18 и 24 ч.

После заданного времени выдержки образцы взвешивались с целью определения количества впитавшегося пропиточного состава. Следующим шагом была сушка образцов при комнатной температуре на протяжении 24 ч. По мере высыхания заготовок был отмечен белый налет, что свидетельствует о том, что пропиточный раствор в образцах присутствует.

Проведение огневых испытаний. Использовано устройство «Керамическая труба» (рисунок 1).

Согласно требованиям ГОСТ по организации прибора, компоненты должны соответствовать следующим требованиям [6]:

- керамический короб с наружными размерами 120 х 120 х 300 мм и толщиной стенок $(16 \pm 2)$ мм;

- металлическая подставка для крепления керамического короба, которая имеет створки произвольной конструкции (или другое приспособление) для регулирования подачи воздуха в зону горения образца;

- газовая горелка, входящая внутрь керамического короба в его центре с отклонением от оси не более 2 мм; 
- автоматический потенциометр (класс точности 0,5) с пределом измерений от $0{ }^{\circ} \mathrm{C}$ до $800{ }^{\circ} \mathrm{C}$;

- держатель образца, фиксирующий положение испытываемого образца в центре керамического короба на расстоянии $(60 \pm 2)$ мм от газовой горелки;

- зонт, расположенный в рабочем положении соосно коробу и на расстоянии $(40 \pm 2)$ мм выше его. Для установки образца должна быть предусмотрена возможность отвода зонта;

- термоэлектрический преобразователь с пределами измерения от $0{ }^{\circ} \mathrm{C}$ до $900{ }^{\circ} \mathrm{C}$. Горячий спай термоэлектрического преобразователя должен располагаться в центре верхнего патрубка зонта;

- ротаметр типа РМ-А-I с верхним пределом измерения расхода газа до 100 л/ч и погрешностью измерения расхода газа не более 4 \% [5].

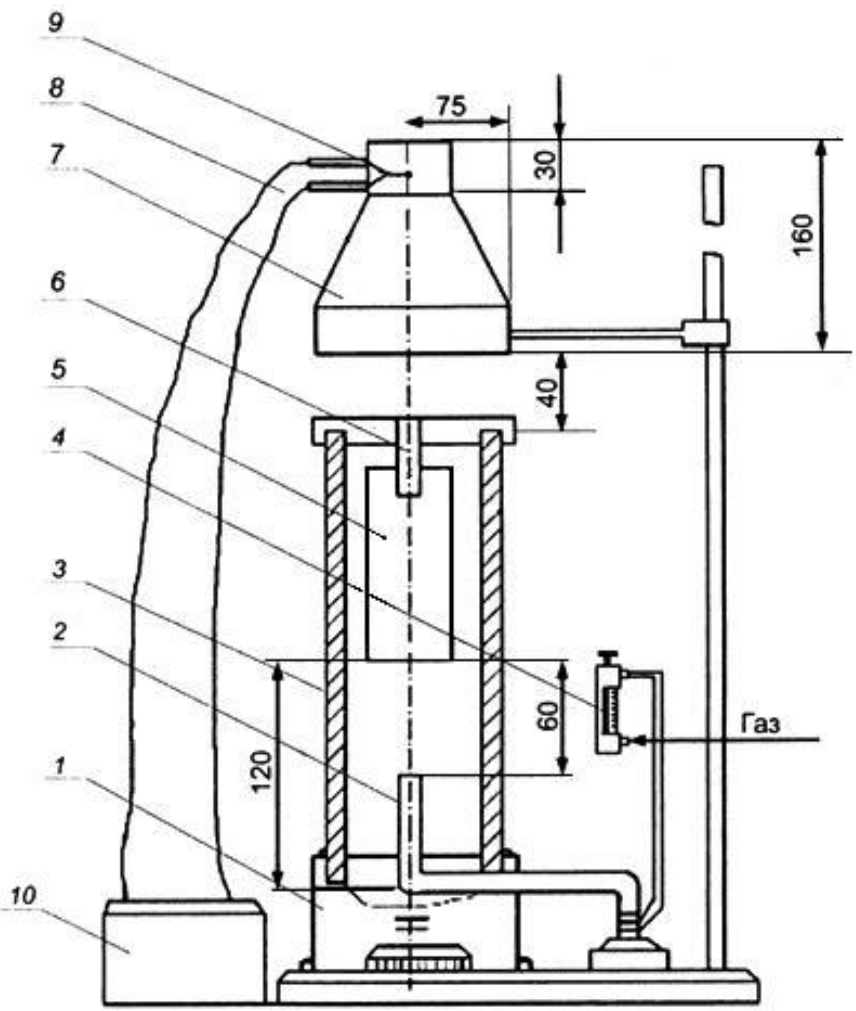

1 - подставка; 2 - газовая горелка; 3 - керамический короб;

4 - ротаметр; 5 - образец; 6 - держатель образца; 7 - зонт;

8 - термоэлектрический преобразователь; 9 - верхний патрубок зонта;

10 - автоматический потенциометр

Рисунок 1. Схема установки «Керамическая труба» 
Удостоверившись, что наша установка соответствует требованиям, проводим испытания, предварительно засекая время до тления и время горения. Далее взвешиваем образцы.

В ходе работы были получены результаты, представленные на рисунках 2-4.

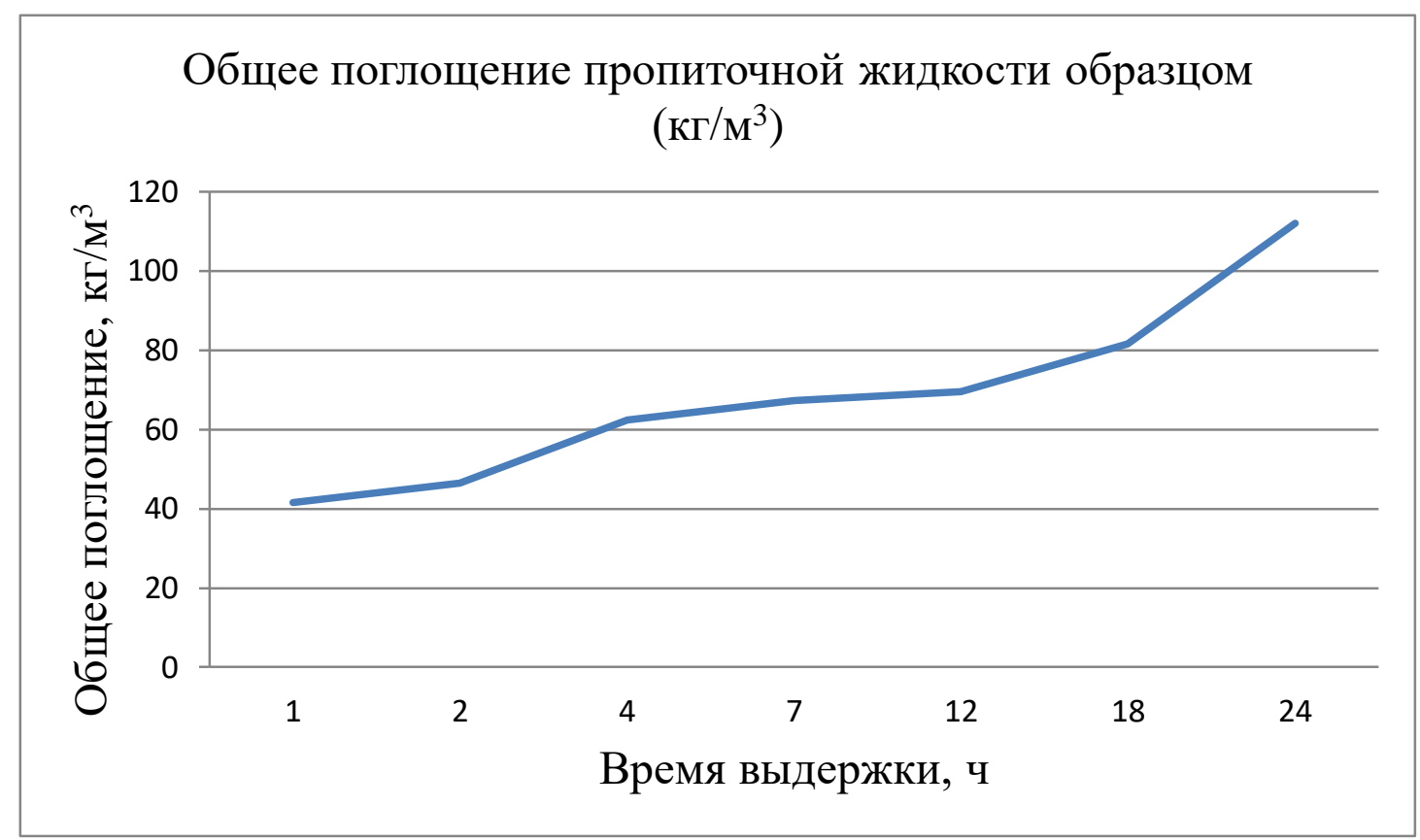

Рисунок 2. Диаграмма общего поглощения

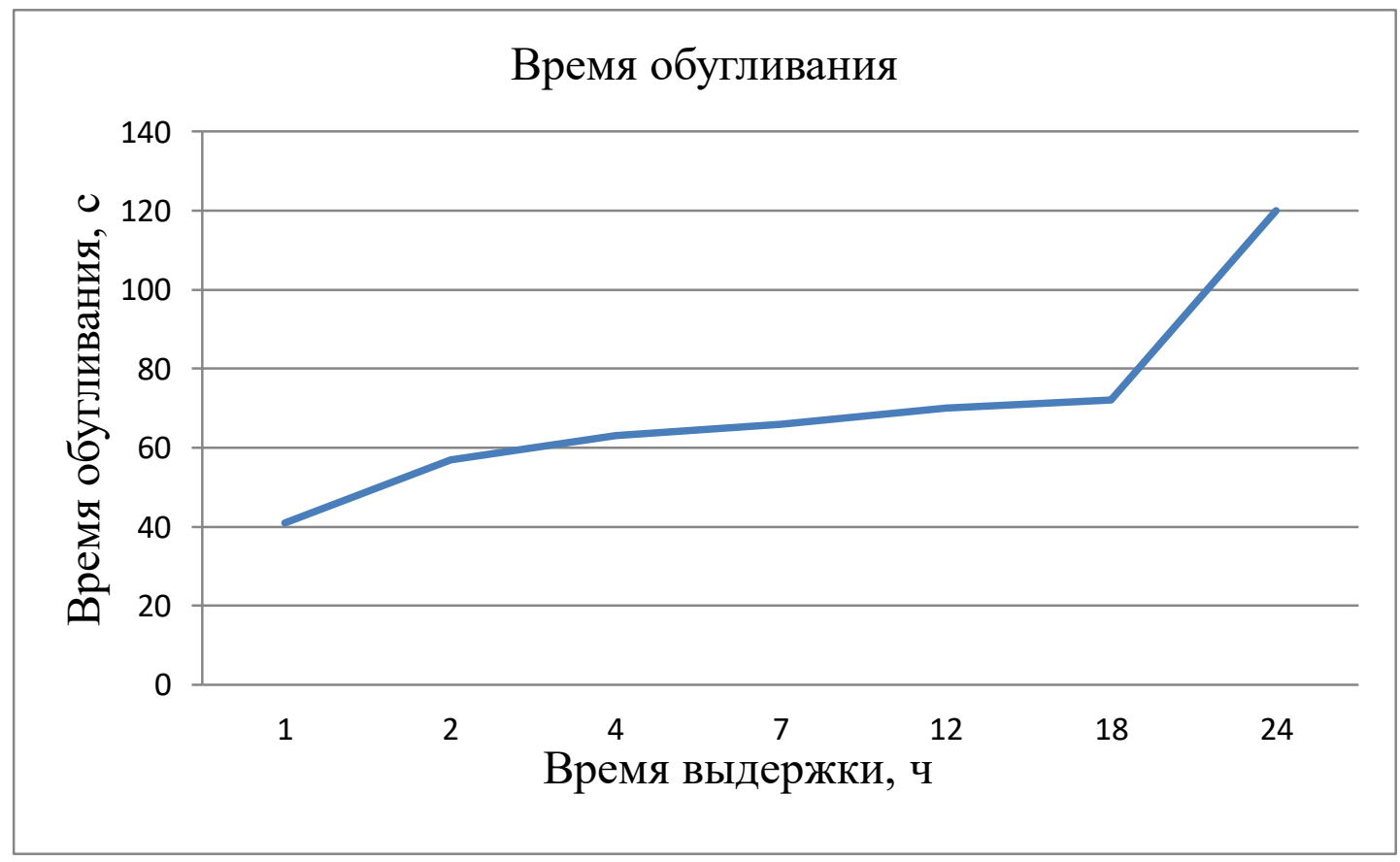

Рисунок 3. Диаграмма времени обугливания 


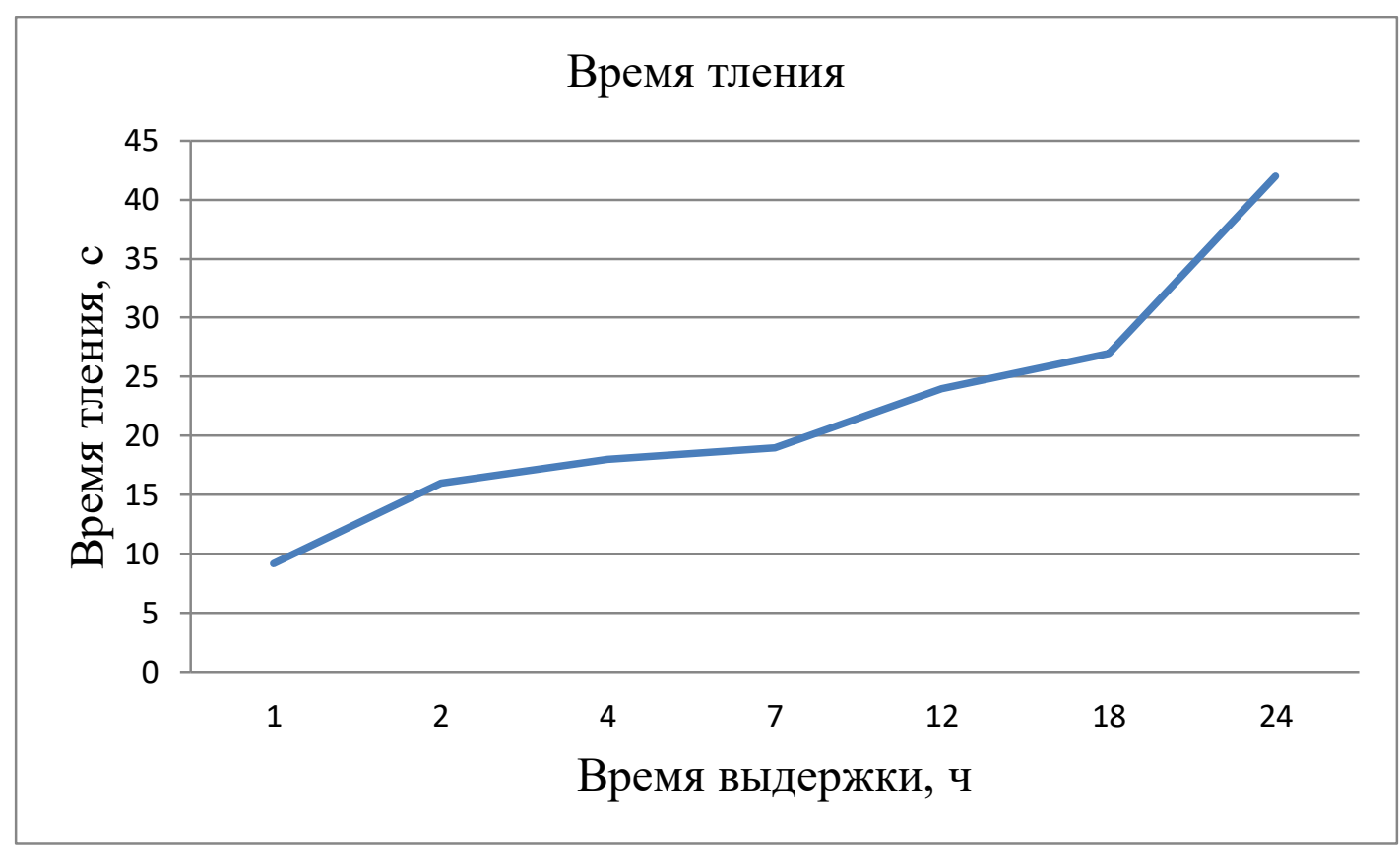

Рисунок 4. Диаграмма времени тления

\section{Выводы}

В результате проведения огневых испытаний установлено, что на рассматриваемом отрезке времени (от 1 до 24 ч) величина поглощения с течением времени растет, что характеризует достаточную глубину пропитки древесины антипиреновым составом. Установлено, что с увеличением времени выдержки образцов время тления возрастает монотонно. Похожая ситуация наблюдается и со временем обугливания, но следует отметить, что график оказался более монотонным на отрезке времени от 4 до 18 ч.

\section{Список используемых источников}

1. Леонович А.А., Шалун Г.Б. Огнезащита древесных плит и слоистых пластиков. М.: Лесная промышленность, 1974. 128 с.

2. Конкин А.А., Кудрявцев Г.И., Щетинин А.М., Дружинина Т.В., Мухин Б.А. Термо-, жаростойкие и негорючие волокна. М.: Химия, 1978. $422 \mathrm{c}$. 
3. Газизов А.М., Кузнецова О.В., Шарафутдинов А.А., Еникеев М.И. Повышение стойкости композиционного древесного материала // Сетевое издание «Нефтегазовое дело». 2018. № 4. С. 182-193. DOI: 10.17122/ogbus2018-4-182-193. URL: http://ogbus.ru/files/ogbus/issues/4_2018/ogbus_4_2018 _p182-193_GazizovAM_ru.pdf (дата обращения: 19.08.2016).

4. Хафизов Ф.Ш., Газизов А.M, Муратов Д.Ф. Применение антипиренов для древесного материала // Сетевое издание «Нефтегазовое дело». 2019. № 2. С. 16-31. DOI: 10.17122/ogbus-2019-2-16-31. URL: http://ogbus.ru/files/ogbus/issues/2_2019/ogbus_2_2019_p16-31.pdf (дата обращения: 05.09.2019).

5. ГОСТ Р 53292-2009. Огнезащитные составы и вещества для древесины и материалов на ее основе. Общие требования. Методы испытаний. М.: Стандартинформ, 2009. 21 с.

6. ГОСТ 16363-76. Средства огнезащитные для древесины. Методы определения огнезащитных свойств. М.: ИПК Издательство стандартов, 2002. 8 c.

\section{References}

1. Leonovich A.A., Shalun G.B. Ognezashchita drevesnykh plit i sloistykh plastikov [Fire Protection of Wood Boards and Laminated Plastics]. Moscow, Lesnaya promyshlennost Publ., 1974. 128 p. [in Russian].

2. Konkin A.A., Kudryavtsev G.I., Shchetinin A.M., Druzhinina T.V., Mukhin B.A. Termo-, zharostoikie i negoryuchie volokna [Heat Resistant and Nonflammable Fibers]. Moscow, Khimiya Publ., 1978. 422 p. [in Russian].

3. Gazizov A.M., Kuznetsova O.V., Sharafutdinov A.A., Enikeev M.I. Povyshenie stoikosti kompozitsionnogo drevesnogo materiala [Increasing the Stability of Composite Wood Material]. Setevoe izdanie «Neftegazovoe delo» - Online Edition «Oil and Gas Business», 2018, No. 4. pp. 182-193. DOI: 10.17122/ogbus-2018-4182-193. URL: http://ogbus.ru/files/ogbus/issues/ 4_2018/ogbus_4_2018_p182193_GazizovAM_ru.pdf (accessed 19.08.2016). [in Russian]. 
4. Khafizov F.Sh., Gazizov A.M, Muratov D.F. Primenenie antipirenov dlya drevesnogo materiala [Fire Retardants Application for Wood Material]. Setevoe izdanie «Neftegazovoe delo» - Online Edition «Oil and Gas Business», 2019, No. 2, pp. 16-31. DOI: 10.17122/ogbus-2019-2-16-31. URL: http://ogbus.ru/ files/ogbus/issues/2_2019/ogbus_2_2019_p16-31.pdf (accessed 05.09.2019). [in Russian].

5. GOST $R$ 53292-2009. Ognezashchitnye sostavy $i$ veshchestva dlya drevesiny $i$ materialov na ee osnove. Obshchie trebovaniya. Metody ispytanii [State Standard R 53292-2009. Fire Retardant Compositions and Substances for Wood. General Requirements. Test Methods]. Moscow, Standartinform Publ., 2009. 21 p. [in Russian].

6. GOST 16363-76. Sredstva ognezashchitnye dlya drevesiny. Metody opredeleniya ognezashchitnykh svoistv [State Standard 16363-76. Protective Aids for Wood. Method for Determining Fire Protective Properties]. Moscow, IPK Izdatel'stvo standartov Publ., 2002. 8 p. [in Russian].

\section{Сведения об авторах}

\section{About the authors}

Газизов Асгат Мазхатович, д-р техн. наук, профессор кафедры «Пожарная и промышленная безопасность», УГНТУ, г. Уфа, Российская Федерация

Asgat M. Gazizov, Doctor of Engineering Sciences, Professor of Fire and Industrial Safety Department, USPTU, Ufa, Russian Federation

e-mail: ashatgaz@mail.ru 
Дудниченко Илья Игоревич, студент кафедры «Автоматизация и инновационные технологии», Уральский государственный лесотехнический университет, г. Екатеринбург, Российская Федерация

Ilya I. Dudnichenko, Student of Automation and Innovative Technologies Department, Ural State Forestry Engineering University, Yekaterinburg, Russian Federation

e-mail: dudnichenko7@gmail.com

Хафизов Фаниль Шамилевич, д-р техн. наук, профессор, заведующий кафедрой «Пожарная и промышленная безопасность», УГНТУ, г. Уфа, Российская Федерация

Fanil Sh. Khafizov, Doctor of Engineering Sciences, Professor, Head of Fire and Industrial Safety Department, USPTU, Ufa, Russian Federation e-mail: pkpb@mail.ru 